\title{
Epithelial Cells Count and the Ratio of Leukocytes and Epithelial Cells as the Criteria to Determine Qualified Specimen for Community-Acquired Pneumonia (CAP)-causing Pathogens Identification
}

\author{
Ade Dharmawan $^{1, *}$, Anis Karuniawati ${ }^{2}$, Pratiwi Pudjilestari Sudarmono ${ }^{2}$, Delly Chipta Lestari², \\ Cleopas Martin Rumende ${ }^{3}$
}

\author{
${ }^{1}$ Department of Microbiology, Faculty of Medicine, Krida Wacana Christian University, Jl. Arjuna Utara No. 6, Jakarta, Indonesia \\ ${ }^{2}$ Department of Microbiology, Faculty of Medicine, Universitas Indonesia/Cipto Mangunkusumo General Hospital, J1. Pangeran Diponegoro No.71, \\ Jakarta, Indonesia \\ ${ }^{3}$ Department of Internal Medicine, Respirology and Critical Illnes Division, Faculty of Medicine, Universitas Indonesia/ \\ Cipto Mangunkusumo General Hospital, Jl. Pangeran Diponegoro No.71, Jakarta, Indonesia \\ *Corresponding author. E-mail: ade.dharmawan86@gmail.com
}

Received date: Jun 11, 2019; Revised date: Oct 29, 2019; Accepted date: Nov 4, 2019

\section{Abstract}

$\mathrm{B}$ ACKGROUND: Community-acquired pneumonia (CAP) is the most common infectious with serious rate of morbidity and mortality. Recent conventional method only described $30-50 \%$ of CAP etiology. Sputum specimen quality assessment is important to obtain an accessible CAP-causing pathogens identification.

METHODS: This was a prospective descriptive study involving 100 specimens from CAP-diagnosed subjects in Budhi Asih Regional General Hospital inpatien $t$ care. We assessed three gram-staining criteria for specimen quality determination, and continued by bacterial identification.

RESULTS: All specimens were qualified according to criteria II, while only 94 and 96 specimens were qualified according to criteria I and III, respectively. Sixty-five specimens could be identified by culture and pneumoCLART polymerase chain reaction (PCR) examination, and the 35 specimens remained unknown. Ten out of those 35 specimens were positive after analyzed by Acid-fast Bacilli (AFB) test. The pathogens we identified including Klebsiella pneumoniae (29.6\%), Acinetobacter baumanii (10.2\%), Enterobacter cloacae (4.6\%), Pseudomonas aeruginosa (4.6\%), Staphyloccocus aureus (4.6\%), Moraxella catarrhalis (3.7\%), Enterobacter aerogenes (2.8\%), Escherichia coli (2.8\%), Streptococcus pneumoniae (1.9\%), Mycoplasma pneumoniae (1.9\%) and Citrobacter koseri (0.9\%).

CONCLUSION: There were no significant differences among the three criteria for sputum specimen quality assessment, based on culture and pneumoCLART examination. We suggest that criteria II could be used to avoid many specimen rejections while good quality specimens still attained for accessible bacteria identification.

KEYWORDS: community-acquired pneumonia, sputum, gram stain, pathogens, bacteria

Indones Biomed J. 2020; 12(1): 34-9

\section{Introduction}

Community-acquired pneumonia (CAP) is the most common infectious disease, and particularly becomes the most life-threatening infection in developing countries. $(1,2)$ Pneumonia is found as one of the 10 highest inpatient care cases in Indonesia including $53.95 \%$ males and $46.05 \%$ females, with $7.6 \%$ crude fatality rate (CFR), counted as the highest compared to other diseases.(3)

CAP is defined as the lung parenchyma infection that is acquired outside the hospital or healthcare facility, or pneumonia that occurred less than 48 hours before hospital admission. $(4,5)$ Understanding the etiology of CAP is 
important to determine the adequate antimicrobial treatment. $(6,7)$ A study in the United States found the most common pathogens for CAP were human rhinovirus, followed by the influenza virus, and Streptococcus pneumoniae.(8) Studies in Norway and Iran found Streptococcus pneumoniae to be the most common causative pathogen.(7,9) Another study in Semarang, Indonesia, identified influenza virus, followed by Klebsiella pneumoniae and Streptococcus pneumoniae as the most common causal pathogens for CAP.(6) Meanwhile in Persahabatan Hospital, Jakarta, Indonesia, Klebsiella pneumoniae was identified as the most common, followed by Acinetobacter baumannii.(3)

The conventional method currently applied to identify CAP-causing pathogens performed by sputum gram staining and culture examination, but so far only $30-50 \%$ of the pathogens could be identified.(10) The gram staining is an easy, cheap and simple method. However, the usefulness of gram staining method in CAP patients was still in debate, due to the difficulty in determination for suitable criteria to avoid too many specimen rejection, while good quality specimens were still obtained, so the precise information could be provided for CAP initial therapy.(11-13)

Some criteria that commonly used recently to assess the sputum quality including: 1) Good quality specimen is defined as the number of epithelial cells $<10 /$ low-power field (LPF) or white blood cells $(\mathrm{WBC})>10$ times of epithelial cells, and single bacterial morphology found $\geq 6$ cells/oil immersion field (OIF) on microscopic examination, as in accordance to The American Society for Microbiology (ASM) criteria (14); 2) Good quality specimen is defined as sputum having a total score $\geq 1$ when examined at $100 \mathrm{x}$ magnification, as in accordance to Bartlett's grading system $(13,15)$; 3) Good quality specimen is defined as sputum contains $\geq 10$ WBCs for each one epithelial cell with 400x magnification (16); and 4) Good quality specimen is defined as number of epithelial cells $<10 / \mathrm{LPF}$ or the ratio of leukocytes:epithelial cells ratio is $>2.5$ (6).

In this study, we evaluated three from four criteria mentioned before we continued for culture examination. The specimens that failed to grow in the culture process will be assessed further using polymerase chain reaction (PCR) by pneumoCLART.

\section{Methods}

\section{Study Design and Specimens}

This was a prospective descriptive study. This study has been approved by Medical Research Ethics Committee of Faculty of Medicine, Universitas Indonesia (No. 607/UN2.
F1/ETIK/2016). Sputum collected from subjects admitted with CAP during September 2016 - February 2017 in Budhi Asih Regional General Hospital. CAP was diagnosed based on Indonesian Society of Respirology Guideline, including the epithelial cells of sputum $<10 / \mathrm{LPF}$, or the ratio of leukocytes:epithelial cells ratio is $>2.5$. Specimens were sent to Clinical Microbiology Laboratory, Faculty of Medicine, Universitas Indonesia for microbiological study, including the Gram staining, culture examination, and PneumoCLART examination.

There were three criteria used to define the quality of sputum. Criteria I defined as good quality sputum when the number of epithelial cells $<10 / \mathrm{LPF}$ or WBC $>10$ times of epithelial cells, and single bacterial morphology found $\geq 6$ cells/OIF on microscopic examination (14); criteria II defined good quality sputum when number of epithelial cells $<10 / \mathrm{LPF}$ or the ratio of leukocytes:epithelial cells ratio is $>2.5$ (6); and criteria III defined good quality as sputum contains $\geq 10$ WBCs for each one epithelial cell with $400 x$ magnification (16). Any antibiotic therapy initiated before the microbiology study was recorded.

\section{Bacteria Identification}

The quality of sputum was assessed using three Gram stain criteria (I, II and III). All qualified specimens were then inoculated on blood agar, chocolate agar, and MacConkey agar (Oxoid, Thermofisher Scientific, Massachusetts, USA), for bacterial identification using optochin disk test and incubation in Vitex ${ }^{\circledR}-2$ system (bioMérieux, Marcyl'Étoile, France). Optochin disk test was performed to presumptive identification of Streptococcus pneumoniae from other alpha-hemolytic streptococci, while Vitex ${ }^{\circledR}-2$ system identified the typical bacteria. Atypical bacteria such as Mycoplasma pneumoniae, Chlamydophilla pneumoniae, or fastidious bacteria like Streptoccocus pneumoniae and Haemophilus influenzae was then further investigated using pneumoCLART (Genomica, Madrid, Spain). For bacilli coinfection identification, Acid-fast Bacilli (AFB) test was performed using Ziehl-Neelsen stain.

\section{Data Analysis}

A chi-squared distribution data analysis was performed using SPSS v.21.0 (IBM Corporation, New York, USA).

\section{Results}

Total of 100 sputum specimen were collected from subjects based on the inclusion criteria. Sixty-seven subjects (67\%) were male and 33 subjects (33\%) were female. The age 
ranged from 18-83 years old, with mean of $50.40 \pm 16.73$ years old.

All specimens were qualified after assessed by criteria II, while $94 \%$ and $96 \%$ specimens were qualified based on criteria I and III, respectively. All specimens were then cultured for CAP-pathogen causing identification. The culture examination after specimens' quality assessment results was shown in Table 1.

Table 1. Number of specimens after culture examination of specimens' quality assessment.

\begin{tabular}{lccc}
\hline $\begin{array}{c}\text { Assessment } \\
\text { Criteria }\end{array}$ & $\begin{array}{c}\text { Pathogen } \\
\text { Identified }\end{array}$ & $\begin{array}{c}\text { No Pathogen } \\
\text { Identified }\end{array}$ & Total \\
\hline Criteria I & 56 & 38 & 94 \\
Criteria II & 58 & 42 & 100 \\
Criteria III & 57 & 39 & 96 \\
\hline
\end{tabular}

Forty-two specimens failed to be identified by the culture examination were assessed further using pneumoCLART. Seven specimens were identified successfully using this method and the other 35 were unsuccessful (Table 2, Table 3).

Table 2. Number of specimens with positive pathogen identification after combination assessment of culture examination and pneumoCLART.

\begin{tabular}{lccc}
\hline $\begin{array}{c}\text { Assessment } \\
\text { Criteria }\end{array}$ & $\begin{array}{c}\text { Pathogen } \\
\text { Identified }\end{array}$ & $\begin{array}{c}\text { No Pathogen } \\
\text { Identified }\end{array}$ & Total \\
\hline Criteria I & 63 & 31 & 94 \\
Criteria II & 65 & 35 & 100 \\
Criteria III & 64 & 32 & 96 \\
\hline
\end{tabular}

According to Infectious Diseases Society of America (IDSA) guideline, Mycobacterium tuberculosis should be considered as one of CAP-causing pathogens, although Indonesian Society of Respirology stated the opposite. Due to tuberculosis (TB) endemic in Indonesia, we performed AFB staining using Ziehl-Neelsen method on all specimens and found $25 \%$ specimens were AFB positive. The complete workflow on AFB staining can be found in Figure 1.

During the study, any intravenous antibiotic therapy initiated before specimen collection was recorded. Fortythree percent of specimens were collected before antibiotic therapy, and 53\% specimens collected less than 24 hours after antibiotic therapy. There were no significant differences between both specimens due to culture growth $(p=0.664)$.
Table 3. Bacterial identification on sputum specimens by combination assessment of culture examination and pneumoCLART $(\mathbf{n}=100)$.

\begin{tabular}{lc}
\hline \multicolumn{1}{c}{ Microorganism } & $\begin{array}{c}\text { Total } \\
\mathbf{n}(\mathbf{\%})\end{array}$ \\
\hline Normal flora & $35(32.4 \%)$ \\
Klebsiella pneumoniae & $32(29.6 \%)$ \\
Acinetobacter baumanii & $11(10.2 \%)$ \\
Enterobacter cloacae & $5(4.6 \%)$ \\
Pseudomonas aeruginosa & $5(4.6 \%)$ \\
Staphylococcus aureus & $5(4.6 \%)$ \\
Moraxella catarrhalis & $4(3.7 \%)$ \\
Enterobacter aerogenes & $3(2.8 \%)$ \\
Escherichia coli & $3(2.8 \%)$ \\
Streptococcus pneumoniae & $2(1.9 \%)$ \\
Mycoplasma pneumoniae & $2(1.9 \%)$ \\
Citrobacter koseri & $1(0.9 \%)$ \\
\hline Total & $108 *(100 \%)$ \\
\hline
\end{tabular}

*co-infections were identified in 8 specimens.

\section{Discussion}

The quality of specimens was assessed by three criteria, and we found no significant difference between those three criteria. All specimens were qualified based on criteria II, suggest that criteria II could be recommended to prevent too many specimen rejection, while the good quality of specimens was still accessed.

After culture examination, 67\% specimens (63/94) assessed by criteria I showed a positive identified pathogen, $65 \%(65 / 100)$ by criteria II and $66.7 \%(64 / 96)$ by criteria III. Some studies showed $63 \%$ and $57 \%$ positive identification on their culture.(12,17) Another study in subjects with bacteremic pneumococcal pneumonia, the specimens' quality was assessed by leukocyte count $\geq 10$ times of the epithelial cells, and they found $31 \%$ gram staining positive result.(16) Whereas qualified sample assessed with LPF magnification $(100 \mathrm{x})$ by the number of epithelial cells $<10$ and the number of polymorphonuclear neutrophils (PMN) cells $\geq 25$, and had $45 \%$ and $65 \%$ positive results consecutively on culture. $(18,19)$

The culture examination identified 58\% CAP-causing bacteria out of 100 specimens. We further investigated the rest 42 specimens using pneumoCLART and identified 


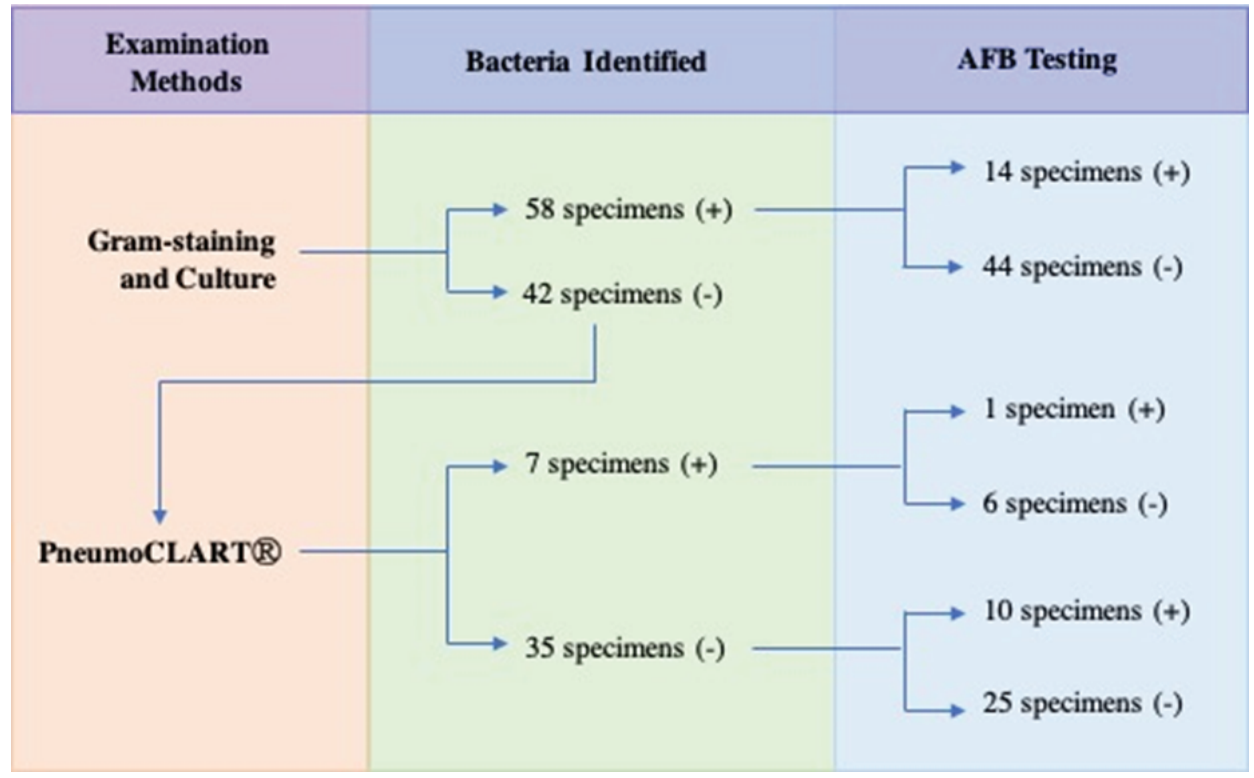

Figure 1. Workflow of AFB staining performed using Ziehl-Neelsen method on specimens after culture examination and PneumoCLART. The assessment meant to investigate any co-infection with bacilli. Twenty-five percents of the specimens were found to be TB positive.

another 7 specimens, while the other 35 were remain unknown. A Study in Semarang, Indonesia found 32\% CAP specimens were unidentified (6), and study in Iran, found $40 \%$ CAP etiology was unknown.(10). Another study even found $76 \%$ unidentified CAP specimens.(20)

The combination of culture examination and pneumoCLART identified 57 single CAP-causing bacteria in our specimens, and 8 specimens with co-infections including Enterobacter cloacae and Enterobacter aerogenes, Klebsiella pneumoniae and Staphylococcus aureus, Klebsiella pneumoniae and Acinetobacter baumanii, Klebsiella pneumoniae and Enterobacter cloacae, Escherichia coli and Acinetobacter baumanii, Pseudomonas aeruginosa and Staphylococcus aureus, Enterobacter cloacae and Staphylococcus aureus, Klebsiella pneumoniae and Escherichia coli.

Most of the CAP-causing bacteria found in our specimens were dominated by Gram-negative bacteria, such as Klebsiella pneumoniae 32 isolates (29.6\%), and Acinetobacter baumanii 11 isolates (10.2\%) from a total of 108 isolates. Another study that was performed in Persahabatan Hospital also found mostly Gramnegative bacteria, such as Klebsiella pneumoniae (34\%) and Acinetobacter baumanii (19.1\%) as the CAP-causing pathogen (21), and a study in Semarang found Klebsiella pneumoniae (14\%) and Streptococcus pneumoniae 13\% as the most CAP-causing pathogens (6). Similarly, the study in Zainoel Abidin Hospital, Banda Aceh found Klebsiella pneumoniae (47.7\%) and followed by Streptococcus pneumoniae (20\%) (22), and a study in Cambodia on acute lower respiratory tract infections subjects found Klebsiella pneumoniae (8\%) as the most frequent infection causal (23).

Different results were showed by another studies, who found Streptococcus pneumoniae as the highest pathogen causing CAP, ranged from 15-38\% while Streptococcus pneumoniae was only found $1.9 \%$ from all cases $(7,9,20,24-$ 26), suggested that different culture media contributed to different bacterial description. In our study, gentamicin blood agar was not performed due to cost limit. Different region of study could also present different pathogens, complicate with the highly frequent antibiotic use in Indonesia, especially in Jakarta, that contributed to change the pattern of pathogen.

The nasopharyngeal bacterial colonization also took part in determining CAP-causing pathogens. Data from a study in Semarang described that $15 \%$ adult aged $45-75$ are Klebsiella pneumoniae carrier and 20\% other Gramnegative bacteria while $11 \%$ children are Streptococcus pneumoniae colonization carrier. $(6,27)$ A smaller prevalence of Streptococcus pneumoniae carrier (3\%) was shown in a study performed in Jakarta, on older subjects group ( $\geq 60$ years old).(28) As the enteric microflora, Klebsiella pneumoniae and other Gram-negative carrier were usually associated with poor sanitation contamination, especially food and water.(29) 
Atypical bacteria, such as Mycoplasma pneumoniae, cannot be identified by microscopic and culture examination due to its low culture-sensitivity, but requires PCR and serology method.(30) Thus, it was not recommended to be performed in routine.

We found that $25 \%$ of our subjects were infected by tuberculosis (TB), showed by AFB positive result. We suggested that AFB or TB culture examination should be considered for specimen with negative microscopic and culture examination results, especially those with negative results of atypical bacteria examination. $(8,31)$

Antibiotic initiation less than 24 hours before the specimen collection showed no significant effect on bacterial culture examination $(p>0.05)$ This was consistent with a study performed in Japan who found $80 \%$ vs. $80 \%$ positive culture between specimens with or without antibiotic less than 24 hours. However, an antibiotic therapy more than 24 hours before specimen collection will significantly reduce the culture growth $(44 \%$ vs. $80 \%)$.(18) Other data also observed a similar result where the culture growth was significantly reduced on specimens with antibiotic initiation more than 24 hours before microbial procedure $(p=0.03) .(15)$

\section{Conclusion}

There were no significant differences among the three criteria for sputum specimen quality assessment, based on culture and PneumoCLART examination, and we suggest that the criteria II could be used to avoid too many specimen rejections while good quality specimens still attained, and bacteria could be well-identified. Specimens could be collected less than 24 hours after antibiotic initiation. We recommend $\mathrm{TB}$ assessment (AFB and culture) to be performed on CAP patients, since in our findings $25 \%$ of CAP subjects were infected with TB as well.

\section{References}

1. Grosso A, Famiglietti A, Luna C. Community-acquired pneumonia due to gram-negative bacteria. Community Acquir Infect. 2015; 2:117. doi:10.4103/2225-6482.172651.

2. Peto L, Nadjm B, Horby P, Ngan TT, van Doorn R, Van Kinh N, et al. The bacterial aetiology of adult community-acquired pneumonia in Asia: A systematic review. Trans R Soc Trop Med Hyg. 2014; 108: 326-37.

3. Soepandi PZ, Burhan E, Nawas A, Giriputro S, Isbaniah F, Agustin H et al. Perhimpunan Dokter Paru Indonesia. 2nd ed. Jakarta: Badan Penerbit FKUI; 2014.
4. Watkins RR, Lemonovich TL. Diagnosis and management of community-acquired pneumonia in adults. Clin Chest Med. 2011; 83: $1299-306$

5. Anand N, Kollef MH. The alphabet soup of radiotherapy. Semin Respir Crit Med. 2009; 30: 39. doi:10.1055/s-0028-1119803.

6. Farida H, Gasem MH, Suryanto A, Keuter M, Zulkarnain N, Satoto $\mathrm{B}$, et al. Viruses and gram-negative bacilli dominate the etiology of community-acquired pneumonia in Indonesia, a cohort study. Int J Infect Dis. 2015; 38: 101-7.

7. Holter JC, Müller F, Bjørang O, Samdal HH, Marthinsen JB, Jenum PA, et al. Etiology of community-acquired pneumonia and diagnostic yields of microbiological methods: a 3-year prospective study in Norway. BMC Infect Dis. 2015; 15: 64. doi:10.1186/ s12879-015-0803-5.

8. Jain S, Self WH, Wunderink RG, Fakhran S, Balk R, Bramley AM, et al. Community-acquired pneumonia requiring hospitalization among U.S. adults. N Engl J Med. 2015; 373: 415-27.

9. Naderi H, Sheybani F, Sarvghad M, Meshkat Z, Nooghabi MJ. Etiological diagnosis of community-acquired pneumonia in adult patients: A prospective hospital-based study in Mashhad, Iran. Jundishapur J Microbiol. 2015; 8(8): e22780. doi: 10.5812/ jjm.22780.

10. Cağlayan Serin D, Pullukçu H, Ciçek C, Sipahi OR, Taşbakan S, Atalay S. Bacterial and viral etiology in hospitalized community acquired pneumonia with molecular methods and clinical evaluation. J Infect Dev Ctries. 2014; 8: 510-8.

11. Fukuyama H, Yamashiro S, Kinjo K, Tamaki H, Kishaba $\mathrm{T}$. Validation of sputum gram stain for treatment of communityacquired pneumonia and healthcare-associated pneumonia: a prospective observational study. BMC Infect Dis. 2014; 14: 534. doi:10.1186/1471-2334-14-534.

12. Mariraj J, Asangi SY, Krishna S, Sonth SB, Ramesh, Shanmugum. Sputum gram stain assessment in relation to sputum culture for respiratory tract infections in a Tertiary Care Hospital. J Clin Diagnostic Res. 2011; 5: 1699-700.

13. Garcia LS, Isenberg HD. Clinical Microbiology Procedures Handbook. Vol 1. Sterling: American Society for Microbiology; 2010.

14. Leber AL. Clinical Microbiology Procedures Handbook. 4th ed. Washington DC: ASM PRESS; 2016.

15. Mokkapati A, Yalamanchili M. Correlation of sputum gram's stain and culture in lower respiratory tract infections. OSR-JDMS. 2013; 8: 6-9.

16. Musher DM, Montoya R, Wanahita A. Diagnostic value of microscopic examination of gram-stained sputum and sputum cultures in patients with bacteremic pneumococcal pneumonia. Clin Infect Dis. 2004; 39: 165-9.

17. Lloveras JJ, Shukr MI, Pinos C, Lindoulsi PG. Usefulness of sputum gram stain and culture for diagnosis of pneumonia in a geriatric institution. J IMAB. 2010; 16(3): 20-2.

18. Miyashita N, Shimizu H, Ouchi K, Kawasaki K, Kawai Y, Obase $\mathrm{Y}$, et al. Assessment of the usefulness of sputum gram stain and culture for diagnosis of community-acquired pneumonia requiring hospitalization. Med Sci Monit. 2008; 14: CR171-6.

19. García-Vázquez E, Marcos MA, Mensa J, de Roux A, Puig J, Font C, et al. Assessment of the usefulness of sputum culture for diagnosis of community-acquired pneumonia using the PORT predictive scoring system. Arch Intern Med. 2004; 164: 1807-11.

20. Shrestha R, Paudel N, Barakoti B, Dhungana D, Sharma P. Etiology and clinical profile of inpatients with Community acquired pneumonia in Manipal Teaching hospital, Pokhara, Nepal. Nepal J Med Sci. 2012; 1: 84-8. 
21. Faisal F, Burhan E, Aniwidyaningsih W, Kekalih A. Penilaian respons pengobatan empiris pada pasien rawat inap dengan pneumonia komunitas. J Respir Indo. 2014; 34: 60-70.

22. Mulyadi, Asmaila N, Yurikno A. Etiology and Risk Factors for Community Acquired Pneumonia in Dr. Zainoel Abidin Hospital, Banda Aceh. Folia Medica Indones. 2011; 47: 127-9.

23. Rammaert B, Goyet S, Beauté J, Hem S, Te V, Try PL, et al. Klebsiella pneumoniaerelated community-acquired acute lower respiratory infections in Cambodia: Clinical characteristics and treatment. BMC Infect Dis. 2012; 12: 3. doi:10.1186/1471-2334-12-3.

24. Johansson N, Kalin M, Tiveljung-lindell A, Giske CG, Hedlund J. Etiology of community-acquired pneumonia: increased microbiological yield with new diagnostic methods. Clin Infect Dis. 2010; 50: 202-9.

25. Wattanathum A, Chaoprasong C, Nunthapisud P, Chantaratchada S, Limpairojn $\mathrm{N}$, Jatakanon A, et al. Community-acquired pneumonia in Southeast Asia: The microbial differences between ambulatory and hospitalized patients. Chest. 2003; 123: 1512-9.

26. Lauderdale TL, Chang FY, Ben RJ, Yin HC, Ni YH, Tsai JW, et al. Etiology of community acquired pneumonia among adult patients requiring hospitalization in Taiwan. Respir Med. 2005; 99: 1079-86.
27. Farida H, Severin JA, Gasem MH, Keuter M, Wahyono H, van den Broek P, et al. Nasopharyngeal carriage of Streptococcus pneumonia in pneumonia-prone age groups in Semarang, Java Island, Indonesia. PLoS One. 2014; 9: 16-8.

28. Safari D, Harimurti K, Khoeri MM, Waslia L, Mudaliana S, A'yun HQ, et al. Staphylococcus aureus and Streptococcus pneumoniae prevalence among elderly adults in Jakarta, Indonesia. Southeast Asian J Trop Med Public Health. 2015; 46: 465-71.

29. Farida H, Severin JA, Gasem MH, Keuter M, van den Broek P, Hermans PW, et al. Nasopharyngeal carriage of klebsiella pneumoniae and other gram-negative bacilli in pneumonia-prone age groups in semarang, indonesia. J Clin Microbiol. 2013; 51: 1614-6.

30. Kashyap S, Sarkar M. Mycoplasma pneumonia : Clinical features and management. Lung India. 2010; 27: 75. doi:10.4103/09702113.63611.

31. Mandell LA, Wunderink RG, Anzueto A, Bartlett JG, Campbell GD, Dean NC, et al. Infectious Diseases Society of America/American Thoracic Society consensus guidelines on the management of community-acquired pneumonia in adults. Clin Infect Dis. 2007; 44(Supplement 2): S27-72. 